\title{
INDOLENT NON-HODGKIN LYMPHOMAS IN THE ELDERLY
}

\section{Sanda BURUIANA ${ }^{\circledR}$, Maria ROBU ${ }^{1}$, Lucia MAZUR-NICORICI ${ }^{1}$, Victor TOMACINSCHII ${ }^{1}$, Minodora MAZUR ${ }^{1}$}

${ }^{1}$ Department of Internal Medicine, State University of Medicine and Pharmacy "Nicolae Testemitanu", Chisinau, Republic of Moldova

Received 17 June 2021, Accepted 02 Aug 2021

hitps://doi.org/10.31688/ABMU.2021.56.3.07

\begin{abstract}
Introduction. Indolent non-Hodgkin lymphoma (NHL) is a lymphoid tumor with increasing morbidity with age.

The objective of the study was to assess the clinical and hematological features of indolent NHL in elderly patients.

Material and methods. The study included patients older than 60 years with indolent NHL, treated in the Oncological Institute, Chisinau, Republic of Moldova. The diagnosis of indolent NHL was established according to the International Histological and Cytological Classification of Hematopoietic and Lymphatic Tissue Pathologies proposed by the World Health Organization in 2016. In all patients, clinical examination, imaging investigations, blood tests, bone marrow aspiration and biopsy were performed.
\end{abstract}

Results. The study included 53 elderly patients: 33 women, 20 men. Marginal zone lymphoma (MZL) predominated in men (70.8\%), follicular lymphoma (FL) in women (62.5\%), small lymphocytic lymphoma (SLL) had almost the same frequency $(49.4 \%$ and $50.6 \%)$ in men and women. In $53 \%$ of cases the onset was in lymph nodes. Advanced stages were diagnosed in

\section{RÉsumé}

Lymphomes non hodgkiniens indolents chez les personnes âgées

Introduction. Le lymphome non hodgkinien (LNH) indolent est une tumeur lymphoïde dont la morbidité augmente avec l'âge.

L'objectif de l'étude était d'évaluer les caractéristiques cliniques et hématologiques du LNH indolent chez les patients âgés.

Materiel et méthodes. L'étude a inclus des patients de plus de 60 ans atteints d'un LNH indolent, traités à l'Institut Oncologique de Chisinau, en République de Moldova. Le diagnostic de LNH indolent a été établi selon la Classification Histologique et Cytologique Internationale des Pathologies des Tissus Hématopoiétiques et Lymphatiques proposée par l'Organisation Mondiale de la Santé en 2016. Chez tous les patients, un examen clinique, des examens d'imagerie, des tests sanguins, une ponction et biopsie de la moelle osseuse ont été utilisés.

Résultats. L'étude a inclut 53 patients âgés: 33 femmes et 20 hommes. Les LNH de zone marginale prédominaient chez les hommes (70.8\%), les LNH folliculaires chez les femmes (62.5\%), et lymphome 
$83.8 \%$ of cases. Bone marrow involvement was detected in $63.2 \%$ of cases.

Conclusions. In our group of study, the most frequent form were SLL, regardless of patients' gender. The onset of indolent NHL occurred more frequently in lymph nodes, mainly in peripheral ones. Independent of the indolent NHL type, the tumour spreads especially in the regional lymph nodes. The involvement of different extra-nodal areas was not identical: the bone marrow was affected most frequently, followed by liver and more rare other organs and tissues. Due to the low degree of malignancy, the extramedullary multiplication of malignant lymphoid cells is slow.

Keywords: non-Hodgkin lymphoma, indolent, elderly patient.

\section{List of abbreviations:}

NHL - non-Hodgkin lymphoma

IPI - International Prognostic Index

FLIPI - Follicular Lymphoma International Prognostic Index

FL - follicular lymphoma

SLL - small lymphocytic lymphoma

MZL - marginal zone lymphoma

\section{INTRODUCTION}

Non-Hodgkin's lymphoma (NHL) is a heterogeneous group of malignant haematological diseases with increasing morbidity, in the world and in Republic of Moldova ${ }^{1,2}$. NHL is one of the most common haematological malignancies ${ }^{2}$, with 450.000 new cases per year ${ }^{3,4}$. According to the clinical evolution, lymphomas are divided into indolent (low-grade malignancy) and aggressive (high-grade malignancy) ${ }^{2,5}$. Indolent NHLs represent a group of lymphomas that historically have been treatable, but not generally curable with specific therapies ${ }^{6}$. Indolent lymphomas affect people of all ages, with the morbidity rate increasing with age, reaching a maximum in patients over 60 years old, the median age being 50 years old ${ }^{7,8}$. The incidence of indolent lymphoma is increasing and is even higher among the elderly population? Half of the newly patients diagnosed with indolent lymphoma are over 60 years of age and can thus be defined as elderly ${ }^{10}$. The average life expectancy in the Republic of Moldova in 2018 was 70.6 years, 66.3 years for men and 75 years for women ${ }^{11}$. The age over 60 years is an unfavorable prognostic factor, included in International Prognostic Index (IPI) and Follicular Lymphoma International Prognostic Index (FLIPI), due to the association of various comorbidities, the impossibility of applying an intensive specific lymphocytaire avait presque la même fréquence chez les hommes et les femmes (49.4\% et 50.6\%). Dans 53\% des cas, le début était dans les ganglions lymphatiques. Des stades avancés ont été diagnostiqués dans 83,8\% des cas. Une atteinte de la moelle osseuse a été détectée dans $63,2 \%$ des cas.

Conclusions. Dans notre groupe d'étude, la forme la plus fréquente était le lymphome lymphocytaire, quel que soit le sexe des patients. L'apparition d'un LNH indolent s'est produite plus fréquemment dans les ganglions lymphatiques, principalement dans les ganglions périphériques. Quel que soit le type de lymphome indolent, la tumeur se propage surtout dans les ganglions lymphatiques régionaux. L'atteinte des différentes zones extra-ganglionnaires n'était pas identique: la moelle osseuse était la plus fréquemment atteinte, suivie du foie et plus rarement d'autres organes et tissus. En raison du faible degré de malignité, la multiplication extramoellaire des cellules lymphoïdes malignes est lente.

Mots-clés: lymphome non hodgkinien, indolent, patient âgé.

treatment (chemotherapy and radiotherapy), with an incomplete response to treatment ${ }^{12}$. Follicular lymphoma represents about $20-30 \%$ of all INHL, marginal zone lymphoma $8 \%$, and small lymphocytic lymphoma $7 \%{ }^{13,14}$.

The clinical picture of lymphomas with low degree of malignancy is manifested by disseminated lymphadenopathy, splenomegaly, long time without $\mathrm{B}$ symptoms of intoxication and with frequent involvement of the bone marrow ${ }^{10,15}$. The clinical approach of elderly patients is a complex issue, and age alone is not enough to establish the treatment strategy. Survival with indolent lymphoma tends to be long and many elderly patients die with their lymphoma rather than of their disease ${ }^{9}$. Often, the purpose of treatment is to ensure the quality of life of the elderly patient with indolent lymphoma.

THE OBJECTIVE OF OUR STUDY was to assess the clinical and hematological features of indolent NHL in elderly patients.

\section{Material AND MEthods}

The study included 53 patients with indolent NHL hospitalized in the Hematology Department of the Public Medico-Sanitary Institution Oncological Institute, Chisinau, Republic of Moldova, between 


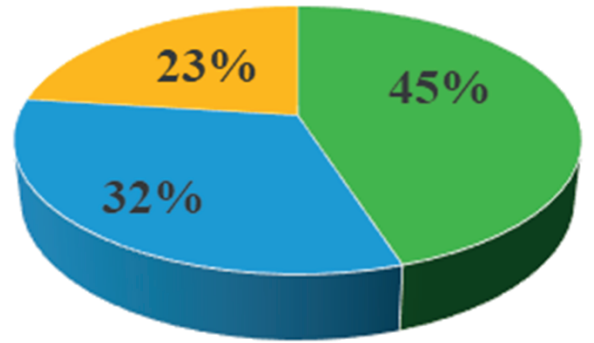

\title{
- small lymphocytic lymphoma " marginal zone lymphoma
}

\author{
- grade I and II follicular lymphoma
}

Figure 1. Distribution of patients according to the morphological type of indolent NHL.

February 2020 and February 2021: 33 women, 20 men, older than 60 years. The criteria for inclusion in the study were: patients' age over 60 years, with histologically confirmed indolent NHL, and patients' agreement to participate in the study. The exclusion criteria were: aggressive NHL, age less than 60 years, patient's disagreement to participate in the study. The diagnosis of indolent NHL was established according to the 2016 revision of the World Health Organization classification of lymphoid neoplasms ${ }^{16}: 24$ patients with small lymphocytic lymphoma (SLL), 17 patients with marginal zone lymphoma (MZL), and 12 patients with follicular lymphoma (FL) grade I and II, who have met the criteria for inclusion in the study. The lymphoma stage was assessed according to the Ann Arbor staging system ${ }^{17}$. The bone marrow examination was performed to assess the invasion of the tumour. The study protocol was approved by the Medical Ethics Committee of the State University of Medicine and Pharmacy "Nicolae Testemitanu", Chisinau, Republic of Moldova (28th of January 2020, session number 32) and written informed consent was obtained from the patients included in the study.

\section{Results}

Out of 68 patients with indolent NHL, 53 (77.9\%) patients were over 60 years old and met the criteria for inclusion in the study. In all cases, the morphological substrate was the B-lymphocyte. The distribution according to the morphological type of indolent lymphoma and gender was: MZL predominated in men (70.8\%), grade I and II, FL in women (62.5\%), and SLL occurred approximately with the same frequency in men and women $(49.4 \%$ and $50.6 \%$, respectively).
In our group of study, the most frequent forms were SLL and MZL (Fig. 1). Independent of the indolent NHL type, advanced stages III and IV were found in $44(83.8 \%)$ cases, mainly stage IV, in 39 (73.5\%) patients. The B symptoms (weight loss of $10 \%$ and more during the last 6 months, fever greater than $38^{\circ} \mathrm{C}$, night sweats), correlated depending on the morphological type of indolent lymphoma and the degree of tumour dissemination. In SLL, which predominated in $45.2 \%$ of elderly patients, the B symptoms were found in only $21.4 \%$, as opposed to the other morphological types of indolent NHL, which indicates a more favorable prognosis. In MZL, the B symptoms were more frequently found in case of primary spleen involvement (77.7\%), which was not confirmed in FL and SLL.

The location of the primary tumour was mainly in the lymph nodes -28 patients (53\%), especially in the peripheral ones - 22 patients (41.5\%). The development of the malignant lymphoid process mainly in the peripheral lymph nodes, considered "visible", unfortunately does not lead to a better addressability of the patient. Primary spleen damage was encountered in $35 \%$ of patients. Rarely, the tumour has developed in other organs and tissues, such as nasopharynx (5\%), or gastrointestinal tract (4\%) (Fig. 2).

Due to the low degree of malignancy, the extramedullary multiplication of malignant lymphoid cells is slow, with a slow increase in the size of the primary tumour (lymph nodes, spleen, etc), and slow expansion of the affected lymphoid organ capsule. Often, the only complaint of a new patient is the presence for a long time (months) of one or more tumours.

The spread of the tumour did not obviously correlate with the type of indolent NHL and patient's 


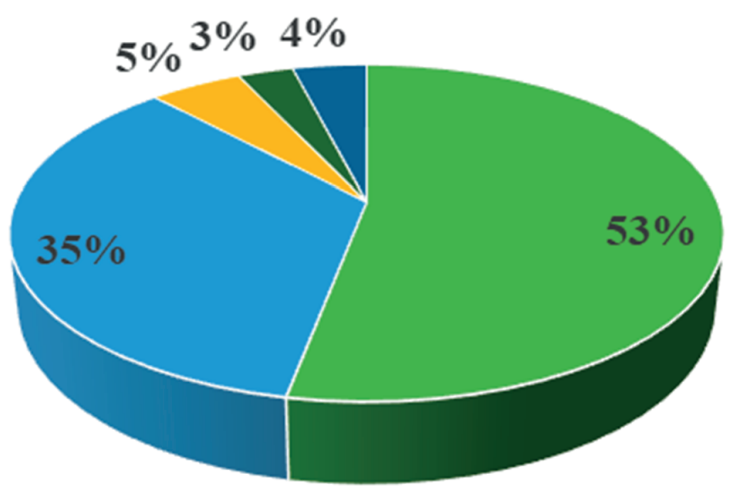

- lymph node

- spleen

- nasopharynx

- gastrointestinal system

- other

Figure 2. Distribution of the location of the primary tumour in elderly patients with indolent NHL.

age, but it depended on the location of the primary tumour. In SLL and FL, the tumour spreaded in the regional lymph nodes with approximately the same frequency ( $88.9 \%$ and $78.5 \%$, respectively), and in MZL, less frequently (65.2\%). In case of development of the primary malignancy in the lymph nodes, either peripheral or internal, the malignant involvement was initially in the regional lymph nodes, later in the distant ones. This has not been confirmed in the case of extra-nodal onset of indolent lymphoma. Extra-nodal metastases, without the involvement of regional and distant lymph nodes, occurred in 32\% of cases in the spleen. The most common extra-nodal metastases were encountered in the bone marrow (63\%) and liver (25\%).

The frequency of bone marrow metastases was the highest in SLL, 23 (95.5\%) patients, followed by MZL (82\%) and less frequently in grade I and II FL (73\%). More frequently, the bone marrow was involved in case of development of the tumour in the spleen (96\%) and lymph nodes (80\%).

\section{Discussion}

The increased prevalence of the elderly population has likely contributed to the increased rate of NHL over time ${ }^{18}$. The incidence of indolent NHL is strongly related to age, the highest incidence being encountered in elderly patients. In the UK, in 2015-2017, more than a third of the new cases (36\%) were diagnosed in people aged 75 years and over ${ }^{19}$. The results of our study are similar, indolent NHL being diagnosed in $77.9 \%$ of cases in patients over 60 years old.

Indolent $\mathrm{NHL}$ is a term used to describe a group of B-cell lymphomas characterized by slow development $^{20}$. B-cell lymphomas account for approximately $90 \%$ of all lymphomas ${ }^{21,22}$. Only $10 \%$ are lymphoid malignancies of T- or NK-cell origin ${ }^{23}$. The results of our study confirmed in $100 \%$ of cases the B-cell origin of lymphoproliferative tumours.

The results of our study demonstrated that in people over 60 years old, SLL develops more frequently than other morphological types of indolent NHL. According to literature, FL is the most common low-grade lymphoma ${ }^{24,25}$.

In our group of study, MZL predominated in men (70.8\%), and FL in women (62.5\%). According to the UK's population-based Haematological Malignancy Research Network (2004-2012), FL and MZL were diagnosed in the elderly (average age 68.05 years) with a different frequency depending on gender: MZL predominated in men (64.6\%) and FL in women $(65.1 \%)^{26}$. Our results are similar with the results of other research in the field.

We have shown that the onset of indolent NHL is more frequently in lymph nodes, 28 (53\%) patients. Shastri et al. in 2017 have found an extra-nodal primary site only in $25 \%$ of cases and in in lymph nodes in $75 \%$ of cases $^{24}$. According to another Moldavian study, that included 78 NHL patients with primary lymph node involvement, aged between 60-84 years, this form of disease had developed more frequently in people aged between 60 to 70 years (73.1\%), especially in the peripheral lymph nodes $(84.7 \%)^{25}$.

Patients with indolent NHL, excluding those with rare localizations, are often diagnosed in advanced stages, with incurable, but highly treatable disease $^{27}$. In our group of study, independent of the indolent NHL type, advanced stages III and IV were found in $83.8 \%$ cases, mainly stage IV, in $73.5 \%$ cases.

Bone marrow is the most common site of extra-nodal involvement in lymphoid malignancies and the frequency of its involvement varies according to lymphoma subtype. The bone marrow involvement at diagnosis is present in the majority of indolent B-cell lymphomas ${ }^{28,29}$. Kumar et al. reported that $55.1 \%$ of NHL patients had bone marrow infiltration ${ }^{30}$. In our 
study, the frequency of bone marrow metastases was the highest in SLL (95.5\%). Park et al. reported similar data, as the involvement of bone marrow in SLL was detected in more than $75 \%$ of cases ${ }^{31}$.

\section{Conclusions}

In our group of study, Small lymphocytic NHL are diagnosed more frequently in elderly patients, regardless of patients' gender. The onset of indolent NHL occurred more frequently in lymph nodes, mainly in peripheral ones. Independent of the indolent NHL type, the tumour spreads especially in the regional lymph nodes. The involvement of different extra-nodal areas was not identical: the bone marrow was affected most frequently, followed by liver and more rare other organs and tissues. Due to the low degree of malignancy, the extramedullary multiplication of malignant lymphoid cells is slow.

A good knowledge of the particularities of indolent NHL in the elderly will contribute to the individualization and development of personalized treatment programs for the elderly.

\section{Author Contributions:}

Conceptualization, S.B. and M.M.; methodology, L.M-N.; software, V.T.; validation, M.M. and M.R.; formal analysis, S.B.; investigation, S.B. and M.M.; resources, S.B.; data curation, S.B. and M.M.; writing-original draft preparation, S.B.; writing-review and editing, M.M, S.B., M.R., V.T.; visualization, M.R. and L.M-N.; supervision, M.M.; project administration, M.M. All the authors have read and agreed with the final version of the article.

\section{Compliance with Ethics Requirements:}

"The authors declare no conflict of interest regarding this article"

"The authors declare that all the procedures and experiments of this study respect the ethical standards in the Helsinki Declaration of 1975, as revised in 2008(5), as well as the national law. Informed consent was obtained from all the patients included in the study"

"No funding for this study"

\section{Acknowledgements:}

None

\section{References}

1. Perry A, Diebold J, Nathwani B, et al. Non-Hodgkin lymphoma in the developing world: Review of 4539 cases from the international Non-Hodgkin Lymphoma Classification Project. Haematologica. 2016; 101(10):1244-1250.
2. Buruiana S. Aspectele clinice, hematologice si imunohistochimice ale limfoamelor non-Hodgkin limfocitare din limfocite mici. INFO-MED. 2016; 2(28):52-58.

3. Intlekofer A, Youne A. Precision therapy for lymphoma-current state and future directions. Nature Reviews Clinical Oncology. 2014; 11(10):585-596.

4. Nemțova M, Maiorova M. Using the achievements of modern genomic technologies for lymphomas. Oncohematologia clinica. 2016; 9(3):265-270.

5. Alessandrino F, Di Piro P, Jagannathan G, et al. Multimodality imaging of indolent $\mathrm{B}$ cell lymphoma from diagnosis to transformation: what every radiologist should know. Insights into Imaging. 2019; 10 (25).

6. Jacobson CA. Indolent lymphomas: pushing the pace with novel agents. Hematology American Society of Hematology Educational Program. 2019;(1):279-286.

7. Chiu BCN, Hon N. Epidemiology and etiology of non-Hodgkin lymphoma. Non-Hodgkin Lymphoma-Springer Cham. 2015; $1-25$.

8. Teras LR, De Santis CE, Cerhan JR, et al. US lymphoid malignancy statistics by World Health Organization subtypes. A Cancer Journal for Clinicians. 2016; htpps.//doi. org/10.3322, caract. 21357. (Accessed on June 02, 2021).

9. Rowentree C. Non-Hodgkin's lymphoma in the elderly. Oncology. 2006; 33-38.

10. Coiffer B. Treatment paradigms in aggressive non-Hodgkin's lymphoma in elderly patients. Clinical Lymphoma, Myeloma and Leukemia. 2002;3(1):4-36.

11. www.statistica.gov.md. (Accessed on June 02, 2021).

12. Castellino A, Santambrogio E, Nicolosi M, et al. Follicular lymphoma: the management of elderly patient. Mediterranean Journal of Hematology and Infectious Diseases. 2017; 9(1): e2017009.

13. Simoneaux R. Evaluation of lenalidomide and rituximab in indolent lymphoma. Oncology Times. 2019; 41(10): 8-9.

14. Sindel A, Al-Juhaishi T, Yazbeck V. Marginal zone lymphoma: state-of-the-art treatment. Current Treatment Options Oncology. 2019; 20(12):90.

15. Cabanillas F, Rivera N, Pardo W. Features: a subset of low-grade lymphomas with a behavior inconsistent with the histologic diagnosis. Clinical Lymphoma, Myeloma and Leukemia. 2016; htpps.//doi.org/10.1016.

16. Swerdlow S, Campo E, Pileri S. et al. The 2016 revision of the World Health Organization classification of lymphoid neoplasms. Blood. 2016; 127 (20): 2375-2390.

17. Armitaje G. Staging Non-Hodgkin Lymphoma. Cancer Journal for Clinicians. 2005; 55:368-376.

18. Barrientos J. Idelalisib for the treatment of indolent non-Hodgkin lymphoma: a review of its clinical potential. OncoTargets and Therapy. 2016; 9: 2945-2953.

19. http://www.wcisu.wales.nhs.uk. (Accessed on June 05, 2021).

20. Lockmer S, Ostenstad B, Hagberg H, et al. Chemotherapy-free initial treatment of advanced indolent lymphoma has durable effect with low toxicity: results from two nordic lymphoma group trials with more than 10 years of follow-up. Journal of Clinical Oncology. 2018; 36(33).

21. Payandeh M, Sadeghi M, Sadeghi E. Advances in non-Hodgkin's lymphoma. American Journal of Cancer Prevention. 2015; 3(5).

22. Sovani V, Harvey C, Haynes A et al. Bone marrow trephine biopsy involvement by lymphoma: review of histopathological features in 511 specimens and correlation with diagnostic biopsy, aspirate and peripheral blood findings. Journal of Clinical Pathology. 2014; 67(5):389-95. 
23. Smedby K, Ponzoni M. The aetiology of B-cell lymphoid malignancies with a focus on chronic inflammation and infections. Journal of Internal Medicine. 2017; 282(5):360-370.

24. Shastri A, Janakiram M, Mantzaris I, et al. Sites of extranodal involvement are prognostic in patients with stage 1 follicular lymphoma. Oncotarget. 2017; 8:78410-78418.

25. Robu M, Tomacinschii V, Corcimaru I, et al. Aspectele clinice ale limfoamelor non-Hodgkin cu afectarea primară a ganglionilor limfatici periferici la persoanele în etate. Sănătate publică, Economie și Management în Medicină. 2020; 4(86): 40-45.

26. Smith A, Crouch S, Lax S et al. Lymphoma incidence, survival and prevalence 2004-2014: sub-type analyses from the UK's Haematological Malignancy Research Network. British Journal of Cancer. 2015; 112: 1575-1584.

27. Lunning M, Voze J. Management of indolent lymphoma: Where are we now and where are we going. Blood Reviews. 2012; 26(6): 279-288.
28. Purtan T. Limfomul Non-Hodgkin. Ghid Cancer. 2016. https://www.ghid-cancer.ro/info/linfomul-non-hodgkin. (Accessed on June 05, 2021).

29. Sehn LH, Scott DW, Chhanabhai M, et al. Impact of concordant and discordant bone marrow involvement on outcome in diffuse large B-cell lymphoma treated with R-CHOP. Journal Clinical Oncology. 2011; 29(11):1452-1457.

30. Kumar S, Rau A, Naik R, Kini H. Bone marrow biopsy in NHL: A morphological study. Indian Journal of Pathology and Microbiology. 2009; 52(3): 332-338.

31. Park Y, Park B, Jeong J et al. Assessment of bone marrow involvement in patients with lymphoma: report on a consensus meeting of the Korean Society of Hematology Lymphoma Working Party. Korean Journal Intern Medicine. 2016; 31(6): 1030-1041. 